\title{
Cancer regression and autoimmunity induced by cytotoxic T lymphocyte-associated antigen 4 blockade in patients with metastatic melanoma
}

\author{
Giao Q. Phan ${ }^{\dagger}$, James C. Yang ${ }^{\dagger}$, Richard M. Sherry ${ }^{\dagger}$, Patrick Hwu $^{\dagger}$, Suzanne L. Topalian ${ }^{\dagger}$, Douglas J. Schwartzentruber ${ }^{\dagger}$, \\ Nicholas P. Restifo ${ }^{\dagger}$, Leah R. Haworth ${ }^{\dagger}$, Claudia A. Seipp ${ }^{\dagger}$, Linda J. Freezer ${ }^{\dagger}$, Kathleen E. Morton ${ }^{\dagger}$, \\ Sharon A. Mavroukakis ${ }^{\dagger}$, Paul H. Duray ${ }^{\ddagger}$, Seth M. Steinberg§, James P. Allisonๆ", Thomas A. Davis", \\ and Steven A. Rosenberg ${ }^{\dagger, t+}$
}

\begin{abstract}
†Surgery Branch, ' 'Laboratory of Pathology, and §Biostatistics and Data Management Section, National Cancer Institute, National Institutes of Health, Bethesda, MD 20892; "Howard Hughes Medical Institute, Department of Molecular and Cell Biology, University of California, Berkeley, CA 94720;

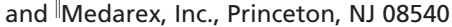

Contributed by James P. Allison, May 27, 2003

Cytotoxic T lymphocyte-associated antigen 4 (CTLA-4) is a critical immunoregulatory molecule (expressed on activated $\mathrm{T}$ cells and a subset of regulatory $T$ cells) capable of down-regulating $T$ cell activation. Blockade of CTLA-4 has been shown in animal models to improve the effectiveness of cancer immunotherapy. We thus treated 14 patients with metastatic melanoma by using serial i.v. administration of a fully human anti-CTLA-4 antibody (MDX-010) in conjunction with s.c. vaccination with two modified HLA-A*0201restricted peptides from the gp100 melanoma-associated antigen, gp 100:209-217(210M) and gp100:280-288(288V). This blockade of CTLA-4 induced grade III/IV autoimmune manifestations in six patients $(43 \%)$, including dermatitis, enterocolitis, hepatitis, and hypophysitis, and mediated objective cancer regression in three patients ( $21 \%$; two complete and one partial responses). This study establishes CTLA-4 as an important molecule regulating tolerance to "self" antigens in humans and suggests a role for CTLA-4 blockade in breaking tolerance to human cancer antigens for cancer immunotherapy.

O ptimal $\mathrm{T}$ cell activation requires interaction between the $\mathrm{T}$ cell receptor and specific antigen (1) (the first signal) and engagement of costimulatory receptors on the surface of the $T$ cell with costimulatory ligands expressed by the antigenpresenting cell (APC) (the second signal). Failure of the T cell to receive a second signal can lead to clonal anergy (2). Two important $\mathrm{T}$ cell costimulatory receptors are $\mathrm{CD} 28$ and cytotoxic T lymphocyte-associated antigen 4 (CTLA-4, CD152) whose ligands on APC are B7-1 and B7-2 $(3,4)$. Although CD28 and CTLA-4 are closely related members of the Ig superfamily (5), they function antagonistically. CD28 is constitutively expressed on the surface of T cells (6), and upon engagement with B7-1 or B7-2, enhances the $\mathrm{T}$ cell receptor-peptide-MHC signal to promote $\mathrm{T}$ cell activation, proliferation, and IL-2 production (3, 7). CTLA-4 is not found on resting T cells but is up-regulated for 2-3 days after T cell activation $(8,9)$. CTLA-4 also binds to B7-1 and B7-2 but with greater affinity than $\mathrm{CD} 28(10)$ and antagonizes $\mathrm{T}$ cell activation, interferes with IL-2 production and IL-2 receptor expression, and interrupts cell cycle progression of activated $\mathrm{T}$ cells (11-14). The overall $\mathrm{T}$ cell response is determined by the integration of all signals, stimulatory and inhibitory.

Because CTLA-4 appears to undermine T cell activation, attempts have been made to block CTLA-4 activity in murine models of cancer immunotherapy. In mice implanted with immunogenic tumors, administration of anti-CTLA-4 Ab enhanced tumor rejection (15), although little effect was seen with poorly immunogenic tumors such as SM1 mammary carcinoma or B16 melanoma. Enhanced antitumor immunity was seen when anti-CTLA-4 Ab was given with granulocyte-macrophage colony-stimulating factor (GM-CSF)-transduced B16 cell vaccine and was associated with depigmentation, suggesting that at least part of the antitumor response was antigen-specific against "self" melanocyte differentiation antigens $(16,17)$. In a transgenic murine model of primary prostate cancer, administrating antiCTLA-4 Ab plus GM-CSF-expressing prostate cancer cells reduced the incidence and histological severity of prostate cancer and led to prostatitis in normal mice, again suggesting an antigen-specific immune response against self-antigens in tumor rejection (18). Furthermore, because many human tumor antigens are normal self-antigens, breaking tolerance against self may be critical to the success of cancer immunotherapy.

Peptide vaccines against melanoma in humans can generate significant peptide- and tumor-specific reactivity, but clinical tumor regression was seen only very rarely unless IL-2 was administered concomitantly (19). The favorable tumor responses from CTLA-4 blockade in conjunction with tumor vaccines in murine models led to interest in using CTLA-4 blockade in human cancer immunotherapy. The production of a human mAb specific for blocking human CTLA-4 engagement to B7 has enabled us to evaluate the impact of CTLA-4 blockade in patients with metastatic melanoma receiving vaccinations with two HLA class I-restricted peptides from the gp100 melanoma-associated antigen, gp100:209-217(210M) and gp100:280-288(288V).

We report here on the development of significant clinical autoimmunity involving multiple normal human tissues and cancer regression in patients with metastatic melanoma receiving this treatment. This study establishes a clear role for CTLA-4 in the maintenance of peripheral tolerance in humans and suggests an important role for CTLA-4 in cancer immunotherapy and in the induction of human autoimmune diseases.

\section{Methods}

Patients and Treatment. All patients were HLA-A $* 0201^{+}$and had progressive stage IV melanoma, Karnofsky performance status $\geq 60 \%$, and no evidence of autoimmune or immunodeficiency disease. Patients had never been immunized against gp100 and had no systemic therapy in the 3 weeks before treatment. All patients signed an informed consent and were treated in an approved protocol in the Surgery Branch at the National Institutes of Health. Patients underwent apheresis before treatment and 3 weeks after every two therapy cycles; peripheral blood mononuclear cells (PBMC) were isolated by Ficoll-Hypaque separation and cryopreserved at $-180^{\circ} \mathrm{C}$ in heat-inactivated human AB serum with 10\% DMSO. The trial used a two-stage

Abbreviations: CTLA-4, cytotoxic T lymphocyte-associated antigen 4; PBMC, peripheral blood mononuclear cells; APC, antigen-presenting cell.

${ }^{\dagger+}$ To whom correspondence should be addressed. E-mail: sar@nih.gov. 
Table 1. Patient characteristics, clinical response, and toxicity

\begin{tabular}{|c|c|c|c|c|c|c|}
\hline Patient & Age/sex & Disease sites & Prior therapy & $\begin{array}{l}\text { No. of cycles } \\
\text { received* }\end{array}$ & $\begin{array}{c}\text { Response } \\
\text { (mos.) }\end{array}$ & Toxicity (grade III/IV) \\
\hline 1 & $52 / \mathrm{M}$ & Lung & $\mathrm{I}, \mathrm{S}$ & 2 & PR $(15+)$ & Enterocolitis; dermatitis \\
\hline 2 & $40 / \mathrm{F}$ & Supraclavicular lymph node & C, I, S & 1 & NR & Dermatitis; vitiligo $^{\dagger}$ \\
\hline 3 & $39 / \mathrm{M}$ & Lung, mediastinum, subcutaneous & $\mathrm{S}$ & 6 & NR (mixed) & \\
\hline 4 & $55 / \mathrm{F}$ & Skin, subcutaneous & $\mathrm{I}, \mathrm{S}$ & 1 & NR & Pulmonary infiltrates $^{\dagger}$ \\
\hline 5 & $67 / M$ & Liver, retroperitoneum, subcutaneous & $C, I, R, S$ & 4 & NR & $\mathrm{ANA}+{ }^{+}$ \\
\hline 6 & $59 / M$ & Lung, subcutaneous & $\mathrm{I}, \mathrm{S}$ & 4 & NR & Vitiligo $^{\dagger}$ \\
\hline 7 & $48 / \mathrm{M}$ & Lung, brain, adrenal, subcutaneous & $\mathrm{I}, \mathrm{S}$ & 2 & NR & \\
\hline 8 & $48 / \mathrm{M}$ & Lung, liver, adrenal, mesentery, subcutaneous & C, I, S & 2 & NR & \\
\hline 9 & $53 / \mathrm{M}$ & Mediastinum, mesentery, skin & $\mathrm{I}, \mathrm{R}, \mathrm{S}$ & 2 & NR & Colitis \\
\hline 10 & $62 / M$ & Lung, hilum & $\mathrm{C}, \mathrm{I}, \mathrm{S}$ & 2 & NR (mixed) & \\
\hline 11 & $54 / \mathrm{M}$ & Lung, brain, subcutaneous & $\mathrm{C}, \mathrm{S}$ & 5 & $\mathrm{CR}(12+)$ & Hypophysitis \\
\hline 12 & $43 / \mathrm{M}$ & Subdiaphragm, muscle, subcutaneous & $\mathrm{I}, \mathrm{S}$ & 3 & NR & Hepatitis; ANA $+^{+}$ \\
\hline 13 & $49 / \mathrm{F}$ & Lung, subcutaneous & $\mathrm{C}, \mathrm{I}, \mathrm{S}$ & 4 & CR $(11+)$ & Dermatitis \\
\hline 14 & $63 / M$ & Lung, pelvic lymph node & $\mathrm{S}$ & 4 & NR & \\
\hline
\end{tabular}

ANA, antinuclear Ab; C, chemotherapy; CR, complete response; F, female; I, immunotherapy; M, male; NR, no response; PR, partial response; R, radiotherapy; S, surgery.

*One treatment cycle consists of one infusion of anti-CTLA-4 Ab and one vaccination with gp100:209-217(210M) and gp100:280-288(288V) peptides.

${ }^{\dagger}$ Grade I/II toxicity.

optimal design and was intended to accrue to 21 patients to the first stage. Because of the development of grade III/IV autoimmune toxicity in $\geq 3$ patients, accrual ceased after 14 patients were enrolled.

Every 3 weeks, patients received anti-CTLA-4 Ab at $3 \mathrm{mg} / \mathrm{kg}$ i.v. over $90 \mathrm{~min}$, followed by $1 \mathrm{mg}$ of gp100:209-217(210M) peptide (IMDQVPFSV) emulsified in incomplete Freund's adjuvant (IFA) injected s.c. in one extremity and $1 \mathrm{mg}$ of gp100:280-288(288V) peptide (YLEPGPVTV) emulsified in IFA injected in another extremity. The anti-CTLA-4 Ab (MDX010; provided by Medarex) is a fully human $\mathrm{IgG}_{1 \kappa} \mathrm{Ab}$ derived from transgenic mice having human genes encoding heavy and light chains to generate a functional human repertoire. This $\mathrm{Ab}$ has been shown to bind to CTLA-4 expressed on the surface of human T cells and inhibit binding of CTLA-4 to B7 molecules. Synthetic peptides were provided by the National Cancer Institute Cancer Therapy Evaluation Program.

Clinical Response Evaluation and Autoimmunity Screening. All patients underwent computed axial tomography of the chest, abdomen, and pelvis and MRI of the brain within 4 weeks of starting treatment and subsequently after every two therapy cycles. For each patient, the sum of the longest diameters of all tumors (World Health Organization Response Evaluation Criteria in Solid Tumors) before and after therapy was calculated. A partial response was defined as a decrease of $\geq 30 \%$ (but $<100 \%$ ) in the sum of the longest diameters of all evaluable metastases lasting $\geq 1$ month with no new or enlarging tumors; a complete response was the disappearance of all evaluable tumors for $\geq 1$ month. Patients not achieving either a partial or complete response were deemed nonresponders. To screen for autoimmunity, all patients before therapy received an opthalmologic examination that was repeated after 3 months on study. At baseline patients were negative for serum thyroglobulin $\mathrm{Ab}$, rheumatoid factor, and antinuclear Ab; while on study, human anti-human (anti-idiotypic) Ab, erythrocyte sedimentation rate, antinuclear $\mathrm{Ab}$, thyroid-stimulating hormone, and free $\mathrm{T} 4$ were tested every 3 weeks.

Pharmacokinetics. Plasma concentrations of MDX-010 were determined by ELISA using microtiter wells coated with CTLA4-Ig (R \& D Systems). Briefly, dilutions of plasma samples were incubated on the plates, and bound anti-CTLA-4 Ab was detected with alkaline phosphatase-labeled goat anti-human IgG
$\mathrm{F}(\mathrm{ab})$-specific probe, which was developed with $p$-nitrophenyl phosphate substrate.

Immunologic Assessment. For all assays, pretreatment and posttreatment cryopreserved PBMC samples were evaluated simultaneously.

EliSpot assay. PBMC were incubated for $24 \mathrm{~h}$ with peptidepulsed C1R-A 2 APCs in 96-well plates coated with anti-IFN- $\gamma$ $\mathrm{Ab}$ (BioSource, Camarillo, CA). The wells were then washed, coated with biotinylated anti-IFN- $\gamma$ Ab (PharMingen), developed with avidin-alkaline phosphatase, and stained. The number of EliSpots per experiment was corrected by subtracting background spots caused by PBMC incubation with unpulsed APCs.

Flow cytometry and tetramer analysis. PBMC were Fc receptorblocked with mouse IgG (Caltag, Burlingame, CA), stained with fluorochrome-labeled gp100:209-217:HLA-A*0201 tetramers (Beckman Coulter Immunomics, San Diego, CA) or $\mathrm{Ab}$ against selected $\mathrm{T}$ cell markers (BD Biosciences, San Diego), and analyzed by using a FACSCalibur with CELLQUEST (BD Biosciences).

In vitro sensitization assay. As described (19), PBMC were cultured in an Iscove's-based media with $10 \%$ heat-inactivated human AB serum with $1 \mu \mathrm{M}$ native gp100:209-217 or gp100:280-288 peptide and 300 international units/ml of IL-2. After 11-13 days, these T cells were coincubated with peptide-pulsed T2 APC overnight and IFN- $\gamma$ release in the supernatant measured by using ELISA. A positive assay is defined as IFN- $\gamma$ release by posttherapy $\mathrm{PBMC} \geq 100 \mathrm{pg} / \mathrm{ml}$ during incubation with a relevant peptide (gp100:209-217 or gp100:280-288), $\geq 2$ times the IFN- $\gamma$ released during incubation with an irrelevant control peptide, and $\geq 2$ times the IFN- $\gamma$ released by pretherapy samples.

\section{Results}

Patient Characteristics. All patients had stage IV melanoma (Table 1); 12 (86\%) had visceral metastases. All had undergone excision of the primary lesion, and six patients $(43 \%)$ had received prior chemotherapy. Eleven patients (79\%) had received prior immunotherapy that included IFN- $\alpha$ (patients 2 , 5-8, 10, 12, and 13), low-dose IL-2 (patients 2, 5, and 13), high-dose IL-2 (patients 4, 7, and 8), whole-cell melanoma vaccines (patients 1, 2, and 6), NY-ESO-1 peptide vaccine (patients 4 and 5), or granulocyte-macrophage colonystimulating factor (patient 9). 
A

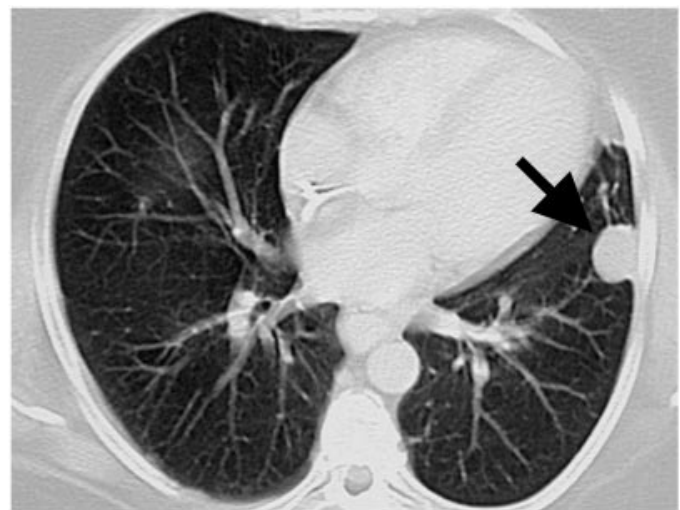

C

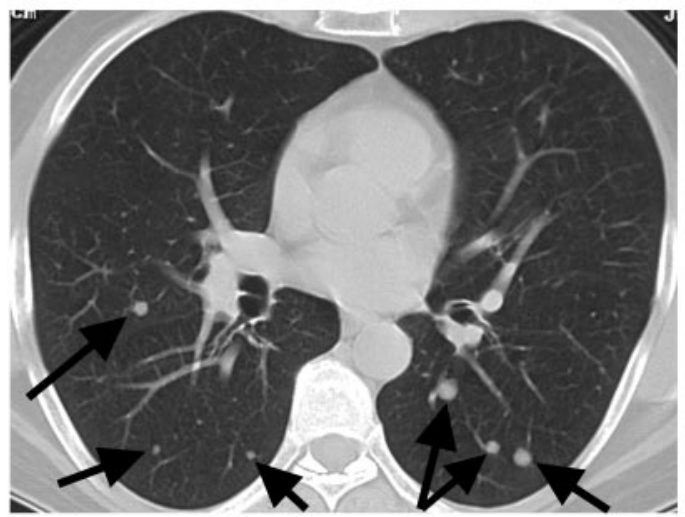

E

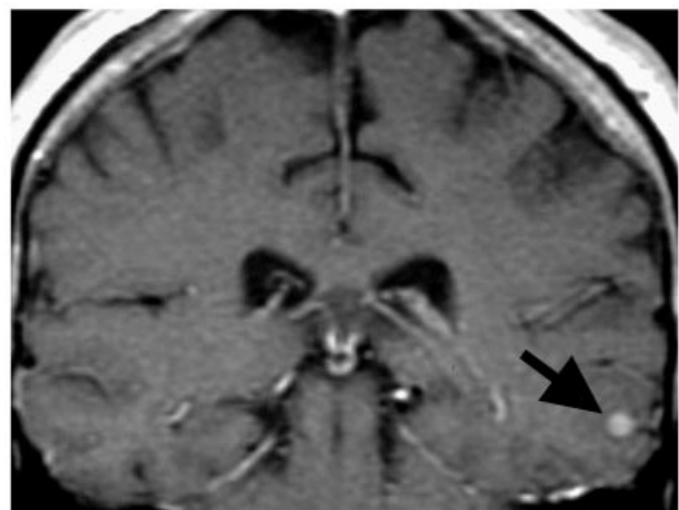

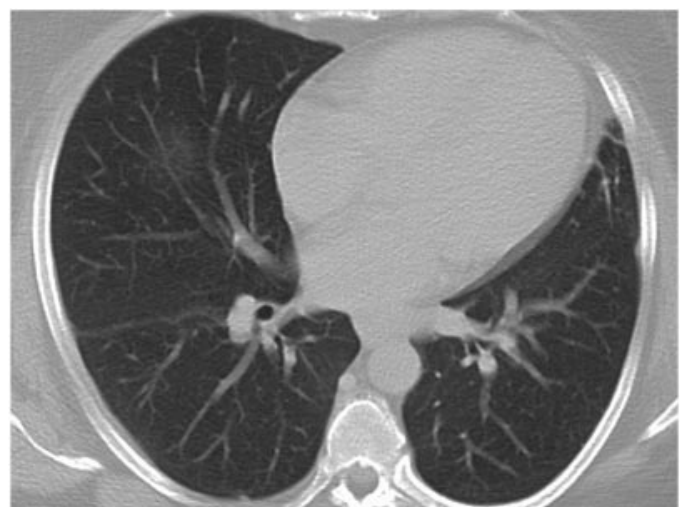

$\mathrm{B}$
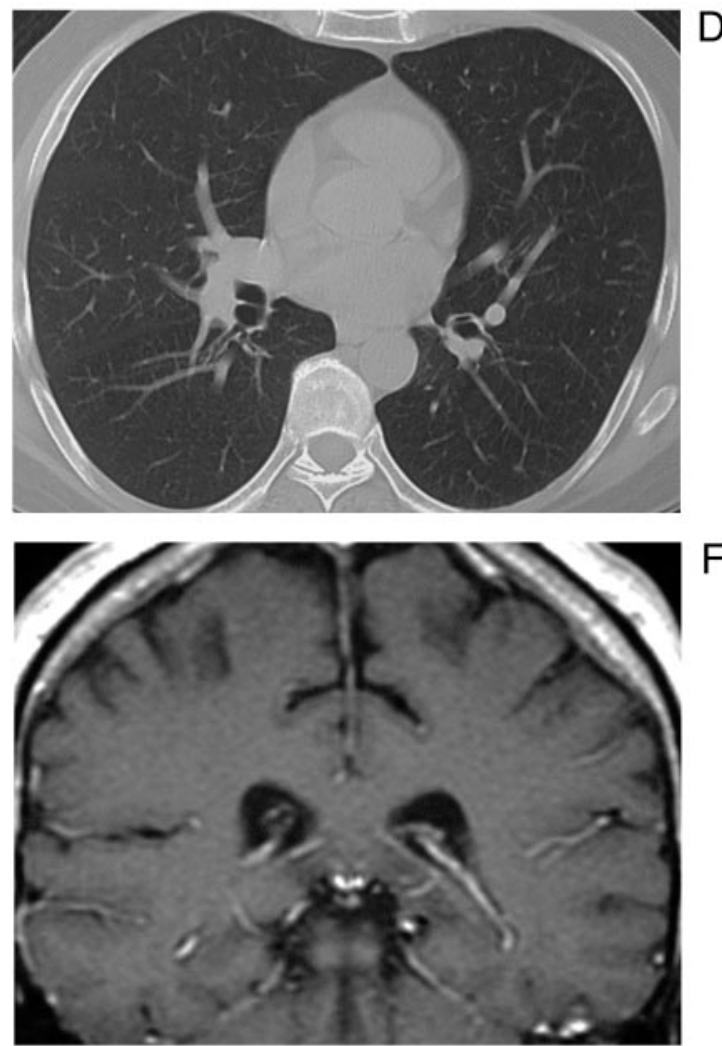

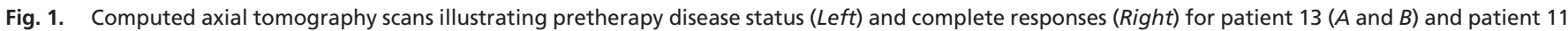
$(C-F)$. Arrows show sites of metastases.

Clinical Responses. Two patients experienced complete tumor responses, and one had a partial response (Table 1). Patient 1 had shrinkage of a solitary lung lesion after two treatment cycles. Patient 13 had complete resolution of a lung mass (Fig. $1 A$ and $B)$ and a s.c. nodule after four cycles. Before therapy, patient 11 had 31 small lung nodules (Fig. 1C), two s.c. masses, and one 0.5 -cm brain metastasis. The brain metastasis grew to $\approx 1 \mathrm{~cm}$ after two treatment cycles (Fig. $1 E$ ). Because of slight shrinkage in the s.c. nodules and some lung lesions, he received three additional cycles and subsequently had complete resolution of all metastases, including the brain lesion (Fig. $1 D$ and $F$ ). Two patients had mixed responses: patient 3 had disappearance of several lung nodules after four cycles but had progression of mediastinal lymph nodes; patient 10 had substantial shrinkage of a large hilar mass and several lung nodules after two cycles but had growth in other lung lesions.

Autoimmune Effects. Grade I/II adverse events included diarrhea (patients 3, 5, and 14), skin rash (patient 14), pulmonary infiltrates associated with mild pleuritic chest pain (patient 4), and vitiligo (patients 2 and 6 after one and two cycles, respectively). Autoimmune screening blood tests (see Methods) were normal except for patients 5 and 12 who developed antinuclear $\mathrm{Ab}$ after two and three cycles, respectively. Six patients $(43 \%)$ developed seven grade III/IV autoimmune toxicities (Table 1), including three patients with dermatitis, two with colitis/ enterocolitis, and one each with hypophysitis and hepatitis. Because autoimmunity in multiple organ sites induced by CTLA-4 blockade in humans has not been reported previously, the detailed histories of these patients are given below.

Patient 1 (a partial responder) developed a generalized erythematous maculopapular rash associated with severe pruritis 1 week after the second treatment. Skin biopsy showed perivascular lymphocytic and eosinophilic infiltrate, papillary dermal edema, and epidermal spongiosis consistent with an "allergic" drug eruption. Two days later, he developed severe diarrhea, requiring i.v. hydration. Upper and lower gastrointestinal en- 
doscopy revealed multiple areas of inflammation and mucosal ulceration; duodenal and colonic biopsies showed marked lymphocytosis, plasmacytosis, and eosinophilia. Immunohistochemical studies showed predominance of $\mathrm{CD}^{+}$cells $\left(\mathrm{CD}^{+}>\right.$ $\mathrm{CD}^{+}$) in the inflammatory infiltrate, polyclonality of the plasma cells, and increased MHC-I and HLA-DR expression in the vasculature and epithelium. A diagnosis of autoimmune enterocolitis was made, and i.v. methylprednisolone was administered, resulting in marked clinical improvement within $24 \mathrm{~h}$. The steroids were tapered over 5 days, and the patient had no further relapse of symptoms.

Patient 2 developed mild generalized pruritis 1 week after receiving her first treatment, which progressed over the next 2 weeks to a severe circumferential, erythematous, edematous macular rash on the extremities in which she had received her vaccine injections (right arm and left leg). Skin biopsy (Fig. 2A) showed epidermal spongiosis, extensive papillary dermal edema, and a prominent lymphocytic and eosinophilic infiltrate with vascular involvement as seen in collagen autoimmunity. Hydroxyzine and diphenhydramine gave symptomatic relief; the rash persisted for several weeks but slowly cleared. The patient developed vitiligo on both upper extremities over the next 3 weeks.

Patient 9 developed diarrhea 11 days after receiving his second treatment. Endoscopy showed pan-colitis. Colon biopsy (Fig. $2 B$ ) revealed severe inflammation with marked cellular infiltration and some crypt abscesses. Immunohistochemical studies demonstrated that the majority of infiltrating lymphocytes were $\mathrm{CD}^{+}$(Fig. $\left.2 \mathrm{C}\right)\left(\mathrm{CD}^{+}>\mathrm{CD}^{+}\right.$, data not shown), plasma cells were polyclonal, and epithelial MHC-I and HLA-DR expression were increased (data not shown). The diarrhea was relieved upon treatment with i.v. methylprednisolone and was controlled with a slow taper of oral dexamethasone.

Patient 11 (a complete responder) developed progressive personality changes and memory problems soon after receiving his fourth and fifth cycles. MRI of the brain showed disappearance of a left temporal metastasis (Fig. $1 E$ and $F$ ); no other abnormalities were found. After the fifth treatment, further evaluation showed undetectable levels of thyroid-stimulating hormone, free T4, adrenocorticotropic hormone, cortisol, growth hormone, prolactin, and testosterone suggestive of panhypopituitarism. These same tests were in the normal range in cryopreserved pretherapy plasma samples. Focused MRI indicated the size of the pituitary gland to be at the upper limit of normal. Because the patient had a complete clinical response (resolution of a brain lesion, two s.c. nodules, and 31 lung metastases), we were reluctant to administer high-dose immunosuppressive steroids to treat the hypophysitis. Subsequently the patient received replacement doses of thyroxine, testosterone, and hydrocortisone, and his personality and memory abnormalities were resolved. Follow-up pituitary MRI done 6 weeks later showed a slight decrease in size, perhaps reflecting decreased inflammation in the gland.

Patient 12 developed abnormal liver enzymes and antinuclear $\mathrm{Ab}$ on routine blood tests done 3 weeks after his third treatment. Other serum tests for autoimmunity were unremarkable. Liver biopsy (Fig. 2D) revealed acute hepatitis with numerous foci of lobular inflammation consisting mainly of lymphocytes with some plasmacytes and eosinophils, consistent with autoimmune processes. Immunohistochemical studies showed a predominantly $\mathrm{CD}^{+}$cellular infiltrate with $\mathrm{CD} 4{ }^{+}$cells mainly in the peri-portal areas and $\mathrm{CD} 8^{+}$cells mainly in the hepatic lobules. Over the next 2 weeks his alanine aminotransferase levels peaked at 2,860 units/liter (normal, 6-41), and aspartate aminotransferase levels peaked at 1,193 units/liter (normal, 9-34). Lowdose oral prednisone therapy was initiated, and all values decreased slowly to normal over the next 4 months.

Patient 13 (a complete responder) developed a severe gener-
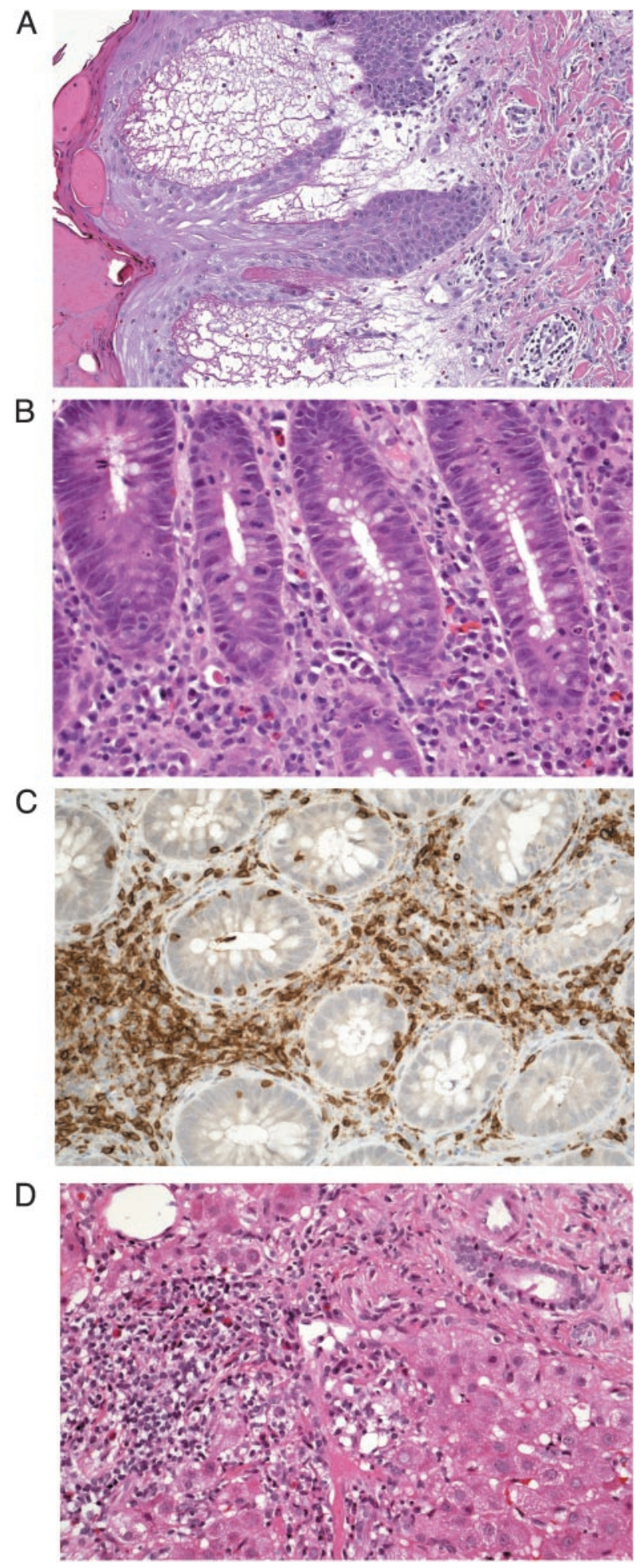

Fig. 2. Histopathologic analyses of selected patients experiencing autoimmune events. (A) Skin biopsy (patient 2) showing severe dermatitis with epidermal spongiosis, papillary dermal edema, and a prominent inflammatory infiltrate in both the superficial and deep dermis. (B) Colon biopsy (patient 9) illustrating severe colitis with infiltration of the lamina propria with neutrophils, lymphocytes, monocytes, plasmacytes, and eosinophils suggestive of autoimmune reactions. Neutrophils and lymphocytes also infiltrate the crypts; numerous mitotic figures are seen in the epithelial cells lining the crypts. (C) Immunohistochemistry of the colon biopsy (patient 9) reveals that the majority of cells are $\mathrm{CD}^{+}$. $(D)$ Liver biopsy (patient 12 ) showing areas of necrosis and lobular inflammation with (mainly) lymphocytic infiltration into the portal triad. (Magnifications: $A, \times 10 ; B-D, \times 20$.) 
Table 2. Flow cytometric analysis of selected T cell surface markers before and after two treatment cycles

\begin{tabular}{|c|c|c|c|c|c|c|c|c|c|c|c|c|}
\hline \multirow[b]{2}{*}{ Patient } & \multicolumn{2}{|c|}{$\mathrm{HLA}^{-D^{+}}{ }^{+}$} & \multicolumn{2}{|c|}{$\mathrm{CD}^{4} 5 \mathrm{RO}^{+}$} & \multicolumn{2}{|c|}{$\mathrm{CD} 69^{+}$} & \multicolumn{2}{|c|}{$\mathrm{CD}^{+}{ }^{+} \mathrm{CD} 25^{+}$} & \multicolumn{2}{|c|}{$\mathrm{CD}_{25}^{+}$} & \multicolumn{2}{|c|}{$\mathrm{CTLA}^{-4^{+}}$} \\
\hline & Pre & Post & Pre & Post & Pre & Post & Pre & Post & Pre & Post & Pre & Post \\
\hline & \multicolumn{2}{|c|}{$\%$ of $\mathrm{CD}^{+}{ }^{+} \mathrm{CD} 4^{+}$} & \multicolumn{2}{|c|}{$\%$ of $\mathrm{CD}^{+}{ }^{+} \mathrm{CD} 4^{+}$} & \multicolumn{2}{|c|}{$\%$ of $\mathrm{CD}^{+}{ }^{+} \mathrm{CD} 4^{+}$} & \multicolumn{2}{|c|}{$\%$ of $\mathrm{CD}^{+}$} & \multicolumn{2}{|c|}{$\%$ of $\mathrm{CD}^{+}$} & \multicolumn{2}{|c|}{$\%$ of $\mathrm{CD} 4^{+} \mathrm{CD} 25^{+}$} \\
\hline 1 & 17.5 & 41.8 & 85.4 & 88.9 & 4.6 & 4.3 & 15.9 & 11.4 & 41.8 & 35.0 & 0.4 & 2.5 \\
\hline 3 & 5.2 & 17.3 & 78.8 & 82.2 & 1.7 & 3.4 & 19.5 & 10.7 & 34.6 & 26.7 & 3.0 & 1.1 \\
\hline 5 & 17.6 & 29.2 & 77.2 & 84.6 & 2.8 & 1.5 & 19.0 & 18.2 & 42.3 & 36.4 & 2.0 & 1.1 \\
\hline 6 & 31.3 & 42.5 & 98.9 & 99.0 & 4.4 & 3.1 & 14.3 & 13.5 & 46.3 & 35.8 & 1.5 & 0.6 \\
\hline 7 & 6.2 & 20.3 & 57.0 & 72.9 & 1.4 & 2.0 & 14.1 & 23.8 & 26.7 & 40.8 & 0.4 & 2.4 \\
\hline 10 & 9.8 & 22.7 & 85.7 & 94.3 & 2.4 & 3.6 & 23.4 & 19.4 & 46.5 & 35.5 & 0.2 & 1.7 \\
\hline 11 & 6.2 & 12.2 & 95.2 & 89.6 & 9.8 & 1.7 & 21.2 & 17.6 & 43.3 & 25.4 & 0.0 & 0.6 \\
\hline 12 & 3.9 & 31.7 & 73.7 & 76.4 & 1.5 & 3.9 & 10.1 & 11.1 & 19.9 & 26.0 & 0.2 & 5.5 \\
\hline 14 & 7.9 & 39.4 & 72.4 & 89.4 & 2.3 & 6.1 & 12.8 & 7.0 & 28.9 & 20.5 & 0.6 & 2.5 \\
\hline \multirow{2}{*}{ Mean $\Delta \pm$ SEM } & \multirow{2}{*}{\multicolumn{2}{|c|}{$\begin{array}{c}+16.8 \pm 2.9(P=0.0004) \\
\% \text { of } \mathrm{CD}^{+}{ }^{+} \mathrm{CD} 4^{-}\end{array}$}} & \multirow{2}{*}{\multicolumn{2}{|c|}{$\begin{array}{c}+5.9 \pm 2.4(P=0.04) \\
\% \text { of } \mathrm{CD}^{+} \mathrm{CD}^{-}\end{array}$}} & \multirow{2}{*}{\multicolumn{2}{|c|}{$\begin{array}{c}-0.1 \pm 1.1(P=0.9) \\
\% \text { of } \mathrm{CD}^{+} \mathrm{CD}^{-}\end{array}$}} & \multicolumn{2}{|c|}{$-1.9 \pm 1.8(P=0.3)$} & \multicolumn{2}{|c|}{$-5.4 \pm 3.2(P=0.13)$} & \multicolumn{2}{|c|}{$+1.1 \pm 0.7(P=0.17)$} \\
\hline & & & & & & & & & & & & \\
\hline 1 & 30.5 & 57.9 & 66.1 & 69.0 & 7.7 & 6.8 & & & & & & \\
\hline 3 & 14.8 & 22.3 & 52.4 & 58.8 & 3.6 & 3.9 & & & & & & \\
\hline 5 & 28.9 & 31.3 & 53.8 & 55.8 & 4.3 & 2.7 & & & & & & \\
\hline 6 & 78.0 & 67.4 & 51.3 & 61.4 & 12.5 & 8.2 & & & & & & \\
\hline 7 & 12.3 & 13.3 & 52.9 & 43.7 & 6.7 & 2.5 & & & & & & \\
\hline 10 & 29.6 & 44.3 & 80.2 & 82.0 & 2.1 & 7.8 & & & & & & \\
\hline 11 & 4.9 & 18.2 & 77.6 & 70.4 & 8.1 & 7.4 & & & & & & \\
\hline 12 & 8.4 & 35.8 & 69.6 & 72.1 & 3.8 & 8.9 & & & & & & \\
\hline 14 & 14.1 & 20.7 & 57.9 & 60.9 & 7.0 & 7.6 & & & & & & \\
\hline Mean $\Delta \pm$ SEM & +10.0 & $=0.04)$ & $+1.4 \pm$ & $=0.51)$ & $0.0 \pm$ & $P=1.0)$ & & & & & & \\
\hline
\end{tabular}

Values compared by using paired $t$ test.

alized erythematous and pruritic rash 1 week after receiving her fourth treatment. Biopsy showed perivascular lymphocytic infiltration with abundant eosinophils in the superficial dermis; immunohistochemical studies revealed that the lymphocytes were mainly $\mathrm{CD}^{+}$cells $\left(\mathrm{CD} 4^{+}>\mathrm{CD}^{+}\right)$. Lymphocytes cultured from a biopsy of the rash were all $\mathrm{CD}^{+}$, and $97 \%$ reacted with gp100:209-217:HLA-A*0201 tetramer (data not shown). The rash resolved slowly upon treatment with hydroxyzine.

Pharmacokinetics. The mean peak of MDX-010 after the first dose was $72 \pm 33 \mu \mathrm{g} / \mathrm{ml}$, and the trough before the second dose was $12 \pm 7 \mu \mathrm{g} / \mathrm{ml}$. Modestly cumulative levels were seen in most patients with repeated dosing. The mean plasma level posttherapy (counting all cycles) was $99 \pm 41 \mu \mathrm{g} / \mathrm{ml}$, which decreased to $17 \pm 10 \mu \mathrm{g} / \mathrm{ml} 3$ weeks later. No clear correlation between plasma concentrations or Ab clearance and tumor regression or toxicity was seen.

Immunologic Response. Using the EliSpot assay to quantify the frequency of cells reactive (secreting IFN- $\gamma$ ) to native gp100:209-217 and gp100:280-288 peptides, PBMC from 11 patients after one to six treatment cycles generated $<10$ (corrected) EliSpots per $10^{5}$ cells, which is below the limit of detection for appropriate assessment of immunization (data not shown). To quantify the frequency of cells capable of recognizing the gp100:209-217:HLA-A*0201 complex, tetramer analysis was performed on PBMC from seven patients after one to four cycles and failed to show a difference between pretherapy and posttherapy samples in binding to gp100:209-217:HLA-A*0201, although $<1 \%$ of $\mathrm{CD}^{+}$cells were tetramer positive in all samples (data not shown).

Using an in vitro sensitization (IVS) assay, which is more sensitive than the EliSpot or tetramer assays to identify the presence of specific immunologic reactivity, all 11 patients with PBMC available for testing developed specific immunity against the native gp100:209-217 peptide after one to four treatment cycles compared with six patients $(55 \%)$ who developed specific immunity against the native gp100:280-288 peptide (data not shown). The results of the EliSpot, tetramer, and IVS assays are consistent with our previous experiences with peptide vaccination alone (19-21) and provide no indication that simultaneous administration of anti-CTLA-4 Ab enhanced responses against the immunizing peptides.

Using flow cytometry to compare surface marker expression on PBMC of nine patients before and after two treatment cycles (Table 2), HLA-DR expression (an activation marker) was significantly increased on posttherapy $\mathrm{CD} 3^{+} \mathrm{CD} 4^{+}$cells $(P=$ 0.0004; paired $t$ test) and $\mathrm{CD}^{+} \mathrm{CD}^{-}$(presumably $\mathrm{CD}^{+}$) cells $(P=0.04) . \mathrm{CD}^{+} \mathrm{CD}^{+}$cells also showed significantly increased expression of CD45RO (a memory cell marker) posttherapy $(P=0.04)$. The percent of various cell populations expressing CD69, CD25, and CTLA-4 did not change.

\section{Discussion}

An understanding of the mechanisms that underlie the ability of the immune system to respond appropriately to "foreign" antigens and yet not react to self-antigens is a fundamental goal of studies in immunology. Although clonal deletion mechanisms may be important in eliminating lymphocyte precursors that bind with high avidity to self-antigens, many alternative mechanisms for inducing peripheral tolerance exist. Immunomodulatory cytokines may play a role in these alternative processes: transforming growth factor- $\beta$ has been shown to inhibit $\mathrm{T}$ cell activation and proliferation (22) and induce FasL expression, leading to activation-induced cell death (23); IL-10 can negatively affect dendritic cell maturation (24), leading to APC apoptosis (25). Depletion of essential nutrients, such as tryptophan or cysteine, from the lymphocyte microenvironment may also contribute to self-tolerance $(26,27)$. Killer inhibitory receptors expressed by natural killer cells, as well as some T cells, prevent activation against noninfected host cells. Furthermore, a subset of $\mathrm{CD} 4{ }^{+} \mathrm{CD} 25^{+} \mathrm{T}$ cells with immunoregulatory capabilities has been shown to prevent $\mathrm{T}$ cell activation and proliferation (28-30). Although the exact mechanism of $\mathrm{CD} 4{ }^{+} \mathrm{CD} 25^{+}$-associated suppression is uncertain, the ubiqui- 
tous presence of CTLA-4 on these regulatory T cells $(31,32)$ suggests that this molecule may be involved.

A negative immunoregulatory role of CTLA-4 was definitively demonstrated in CTLA-4-deficient mice that developed lethal lymphoproliferative disease with infiltration of visceral organs by activated $\mathrm{T}$ cell blasts (33). In animal models, blockade of CTLA-4 has led to enhanced antitumor immunity (15-18) and intensification of $\mathrm{T}$ cell-associated autoimmune encephalomyelitis, colitis, and diabetes $(31,34,35)$. Thus before clinical use, MDX-010 anti-CTLA-4 Ab underwent extensive evaluation in cynomologus monkeys and did not cause any notable clinical or pathological toxicity at repeated i.v. doses from $3 \mathrm{mg} / \mathrm{kg}$ to 30 $\mathrm{mg} / \mathrm{kg}$ in acute and chronic toxicology studies (unpublished data from Medarex).

CTLA-4 blockade in humans given a one-time $3 \mathrm{mg} / \mathrm{kg}$ dose of MDX-010 to seven patients with metastatic melanoma and two with ovarian carcinoma caused no significant toxicity, although all seven melanoma patients developed an asymptomatic grade I rash with skin biopsies showing peri-vascular T cell infiltrates (36). Although objective cancer regressions were not shown, three melanoma patients had evidence of tumor necrosis at biopsied sites.

The study presented here involved anti-CTLA-4 Ab given repeatedly along with tumor-specific peptide vaccinations. Significant grade III/IV autoimmunity in several organ systems was frequent $(43 \%$; 6 patients of 14$)$, thus indicating an important role for CTLA-4 in the maintenance of peripheral tolerance to self-antigens. It is unlikely that the peptide immunizations played a role in inducing autoimmunity in the colon, liver, and pituitary because the target antigens are not thought to be expressed in these tissues and because these autoimmune events were not seen in prior clinical trials using the same vaccines (19-21). Importantly, after discontinuation of further treatment cycles and given supportive care and/or steroid therapy, all patients experiencing autoimmunity recovered from the acute toxicity phase and did not relapse or develop subsequent autoimmune events as the $\mathrm{Ab}$ levels decreased over time.

1. Bretscher, P. \& Cohn, M. (1970) Science 169, 1042-1049.

2. Schwartz, R. H. (1990) Science 248, 1349-1356.

3. Linsley, P. S., Brady, W., Grosmaire, L., Aruffo, A., Damle, N. K. \& Ledbetter, J. A. (1991) J. Exp. Med. 173, 721-730.

4. Linsley, P. S., Brady, W., Urnes, M., Grosmaire, L. S., Damle, N. K. \& Ledbetter, J. A. (1991) J. Exp. Med. 174, 561-569.

5. Brunet, J. F., Denizot, F., Luciani, M. F., Roux-Dosseto, M., Suzan, M., Mattei, M. G. \& Goldstein, P. (1987) Nature 328, 267-270.

6. Gross, J. A., Callas, E. \& Allison, J. P. (1992) J. Immunol. 149, 380-388.

7. Alegre, M. L., Frauwirth, K. A. \& Thompson, C. B. (2002) Nat. Rev. Immunol. 1, $220-228$.

8. Lindsten, T., Lee, K. P., Harris, E. S., Petryniak, B., Craighead, N., Reynolds, P. J., Lombard, D. B., Freeman, G. J., Nadler, L. M., Gray, G. S., et al. (1993) J. Immunol. 151, 3489-3499.

9. Walunas, T. L., Lenschow, D. J., Bakker, C. Y., Linsley, P. S., Freeman, G. J., Green, J. M., Thompson, C. B. \& Bluestone, J. A. (1994) Immunity 1, 405-413.

10. Linsley, P. S., Greene, J. L., Brady, W., Bajorath, J., Ledbetter, J. A. \& Peach, R (1994) Immunity 1, 793-801.

11. Walunas, T. L., Bakker, C. Y. \& Bluestone, J. A. (1996) J. Exp. Med. 183, 2541-2550.

12. Krummel, M. F. \& Allison, J. P. (1996) J. Exp. Med. 183, 2533-2540.

13. Brunner, M. C., Chambers, C. A., Chan, F. K., Hanke, J., Winoto, A. \& Allison, J. P. (1999) J. Immunol. 162, 5813-5820.

14. Greenwald, R. J., Oosterwegel, M. A., van der Woude, D., Kubal, A., Mandelbrot, D. A., Boussiotis, V. A. \& Sharpe, A. H. (2002) Eur. J. Immunol. 32, 366-373.

15. Leach, D. R., Krummel, M. F. \& Allison, J. P. (1996) Science 271, 1734-1736.

16. van Elsas, A., Hurwitz, A. A. \& Allison, J. P. (1999) J. Exp. Med. 190, 355-366.

17. van Elsas, A., Sutmuller, R. P. M., Hurwitz, A. A., Ziskin, J., Villasenor, J., Medema, J. P., Overwijk, W. W., Restifo, N. P., Melief, C. J. M., Offringa, R., et al. (2001) J. Exp. Med. 194, 481-489.

18. Hurwitz, A. A., Foster, B. A., Kwon, E. D., Truong, T., Choi, E. M., Greenberg, N. M., Burg, M. B. \& Allison, J. P. (2000) Cancer Res. 60, 2444-2448.

19. Rosenberg, S. A., Yang, J. C., Schwartzentruber, D. J., Hwu, P., Marincola, F. M., Topalian, S. L., Restifo, N. P., Dudley, M. E., Schwarz, S. L., Spiess, P. J., et al. (1998) Nat. Med. 4, 321-327.
Notably, three patients experienced objective cancer regression, and two experienced mixed responses. In our prior experience with patients receiving one or two HLA class I-restricted peptides alone, no objective cancer regressions were seen in 33 patients $(19,21)$. Clinical responses were seen only when IL-2 was administered concomitantly. Thus it is very likely that the anti-CTLA-4 Ab was involved in mediating cancer regression in the patients described in the current series. The role of the peptide vaccines given with the anti-CTLA-4 Ab in the cancer regression is uncertain. All patients developed $\mathrm{T}$ cell reactivity against the immunizing peptides given in conjunction with the anti-CTLA-4 Ab. The levels of T cell reactivity were consistent with our prior clinical trials using the same peptides without CTLA-4 blockade (19-21). The fact that all three patients with objective responses developed grade III/IV autoimmunity and that two additional patients developed vitiligo suggests that the anticancer response may be associated with some degree of heightened reactivity against self-antigens as well.

Evaluation of lymphocytes from the peripheral circulation showed a significant increase in activation markers after just two cycles of therapy. The increased expression of HLA-DR and CD45RO was especially apparent in the $\mathrm{CD}^{+} \mathrm{CD}^{+}$subset (despite the patients having been vaccinated with two class I-restricted peptides aimed at immunizing $\mathrm{CD} 8^{+}$cells), consistent with the $\mathrm{CD} 4^{+} \mathrm{T}$ cell-driven lymphoproliferative syndrome observed in CTLA-4-deficient mice (33). We did not find a depletion of CTLA-4-expressing cells or $\mathrm{CD} 4{ }^{+} \mathrm{CD} 25^{+}$regulatory $\mathrm{T}$ cells posttherapy. However, these measurements and all tests of immunologic reactivity were conducted by using peripheral blood lymphocytes, which might not reflect the immune status of the tumor microenvironment (37).

This clinical trial has indicated a potential role for CTLA-4 blockade in cancer immunotherapy and has established an important role for CTLA-4 in the maintenance of peripheral tolerance against self antigens in humans. Further study with MDX-010 anti-CTLA-4 Ab either alone or in conjunction with vaccines will be useful to elucidate the potential relationship between autoimmune effects against normal tissues and against tumors and the possible means to dissociate these two events.

20. Pass, H. A., Schwarz, S. L., Wunderlich, J. R. \& Rosenberg, S. A. (1998) Cancer I. Sci. Am. 4, 316-323.

21. Phan, G. Q., Touloukian, C. E., Yang, J. C., Restifo, N. P., Sherry, R. M., Hwu, P., Topalian, S. L., Schwartzentruber, D. J., Seipp, C. A., Freezer, L. J., et al. (2003) J. Immunother. 26, 349-356.

22. Fontana, A., Frei, K., Bodmer, S., Hofer, E., Schreier, M. H., Palladino, M. A., Jr., \& Zinkernagel, R. M. (1989) J. Immunol. 143, 3230-3234.

23. Chen, J. J., Sun, Y. \& Nabel, G. J. (1998) Science 282, 1714-1717.

24. De Smedt, T., Van Mechelen, M., De Becker, G., Urbain, J., Leo, O. \& Moser, M. (1997) Eur. J. Immunol. 27, 1229-1235.

25. Ludewig, B., Graf, D., Gelderblom, H. R., Becker, Y., Kroczek, R. A. \& Pauli, G. (1995) Eur. J. Immunol. 25, 1943-1950.

26. Hwu, P., Du, M. X., Lapointe, R., Do, M., Taylor, M. W. \& Young, H. A. (2000) J. Immunol. 164, 3596-3599.

27. Angelini, G., Gardella, S., Ardy, M., Ciriolo, M. R., Filomeni, G., Di Trapani, G., Clarke, F., Sitia, R. \& Rubartelli, A. (2002) Proc. Natl. Acad. Sci. USA 99, 1471-1476.

28. Suri-Payer, E., Amar, A. Z., Thornton, A. M. \& Shevach, E. M. (1998) J. Immunol. 160, 1212-1218

29. Thornton, A. M. \& Shevach, E. M. (1998) J. Exp. Med. 188, 287-296.

30. Stephens, L. A., Mottet, C., Mason, D. \& Powrie, F. (2001) Eur. J. Immunol. 31, $1247-1254$.

31. Read, S., Malmstrom, V. \& Powrie, F. (2000) J. Exp. Med. 192, 295-302.

32. Woo, E. Y., Yeh, H., Chu, C. S., Schlienger, K., Carroll, R. G., Riley, J. L., Kaiser, L. R. \& June, C. H. (2002) J. Immunol. 168, 4272-4276.

33. Waterhouse, P., Penninger, J. M., Timms, E., Wakeham, A., Shahinian, A., Lee, K. P., Thompson, C. B., Griesser, H. \& Mak, T. W. (1995) Science 270, 985-988.

34. Perrin, P. J., Maldonado, J. H., Davis, T. A., June, C. H. \& Racke, M. K. (1996) J. Immunol. 157, 1333-1336.

35. Luhder, F., Hoglund, P., Allison, J. P., Benoist, C. \& Mathis, D. (1998) J. Exp. Med. 187, 427-432.

36. Hodi, F. S., Mihm, M. C., Soiffer, R. J., Haluska, F. G., Butler, M., Seiden, M. V., Davis, T., Henry-Spires, R., MacRae, S., Willman, A., et al. (2003) Proc. Natl. Acad. Sci. USA 100, 4712-4717.

37. Kammula, U. S., Lee., K. H., Riker, A. I., Wang, E., Ohnmacht, G. A., Rosenberg, S. A. \& Marincola, F. M. (1999) J. Immunol. 163, 6867-6875. 